\title{
Cardiac harms of sofosbuvir: systematic review and meta-analysis
}

Daniel Caldeira M.D. ${ }^{1,2,3}$, Filipe B. Rodrigues ${ }^{1,2}$, Marta Marques ${ }^{1}$, , Carmelo

Sterrantino $^{4}$, Márcio Barra ${ }^{1}$, Nilza Gonçalves ${ }^{1,2}$, Joaquim J. Ferreira ${ }^{1,2}$, João Costa ${ }^{1,2,4,5}$

1. Laboratory of Clinical Pharmacology and Therapeutics, Faculdade de Medicina, Universidade de Lisboa, Portugal.

2. Clinical Pharmacology Unit, Instituto de Medicina Molecular, Lisbon, Portugal.

3. Cardiology Department, Hospital Garcia de Orta, Almada, Portugal.

4. Center for Evidence-Based Medicine, Faculty of Medicine, University of Lisbon. Lisboa, Portugal

5. Portuguese Collaborating Center of the IberoAmerican Cochrane Network, Faculty of Medicine, University of Lisbon. Lisboa, Portugal

Corresponding author: Dr. Daniel Caldeira, Laboratório de Farmacologia Clínica e Terapêutica, Faculdade de Medicina da Universidade de Lisboa, Av. Prof. Egas Moniz, Lisboa, 1649-028, Portugal. E-mail: dgcaldeira@hotmail.com

Phone number: (+351) 2179734 53; Fax number: (+351) 217819688.

Keywords: Sofosbuvir; hepatitis C; cardiac; cardiovascular; bradycardia; arrhythmia 


\section{Abstract}

Introduction: Sofosbuvir is a new direct-acting pyrimidine nucleotide analogue antiviral drug with remarkable efficacy in clinical trials of Hepatitis C treatment. However, observational anecdotal data have recently suggested an increased risk of serious bradycardia among patients treated with sofosbuvir and amiodarone. Therefore, we aimed to better estimate and characterize the cardiac safety of sofosbuvir by performing a systematic review of randomized controlled trials (RCTs).

Methods: Systematic review of RCTs (PROSPERO 2016:CRD42016033109) comparing sofosbuvir versus non-sofosbuvir regimens in chronic Hepatitis C patients. Medline, EMBASE and Cochrane Library were searched up to January 2016. Nonpublished data was obtained from the sofosbuvir marketing authorization holder. Random-effects meta-analysis was performed to derive pooled estimates of Relative Risks (RR) and corresponding 95\% Confidence Interval (CI).

Results: Six trials enrolling 2346 patients (1625 treated with sofosbuvir) were included. The overall risk of bias across studies was moderate. The risk of reported cardiac events (RR 0.87 ; 95\%CI 0.41 to 1.85 ), arrhythmias (RR 0.93 , 95\% CI 0.34 to 2.51 ), bradycardia (RR $0.47 ; 95 \% \mathrm{CI} 0.04$ to 5.20 ) and tachycardia were not significantly different between sofosbuvir and non-sofosbuvir regimens. The risks of reported syncope, presyncope or loss of consciousness, as well as palpitations were similar among sofosbuvir regimens and controls.

Conclusion: The best comparative available evidence from RCTs do not suggest an increased risk of cardiac outcomes, in particular arrhythmias (including bradycardia), among sofosbuvir-treated patients, although the overall quality of the evidence supporting this conclusion is very low. 


\section{Introduction}

Sofosbuvir, a compound present in Sovaldi ${ }^{\circledR}$ (sofosbuvir), Harvoni ${ }^{\circledR}$ (sofosbuvir and ledispavir) and Epclusa ${ }^{\circledR}$ (sofosbuvir and velpatasvir), is a direct-acting pyrimidine nucleotide analogue antiviral drug approved to treat patients with chronic Hepatitis C Virus $(\mathrm{HCV})$ infection. When administered in combination with a second direct-acting antiviral (DAA) agent, with and without pegylated interferon (PegIFN), sofosbuvir showed remarkable efficacy with about $90 \%$ of previously untreated patients with HCV infection achieving sustained virologic response. ${ }^{1}$

In March 2015, the Food and Drug Administration (FDA) issued a label update for sofosbuvir, following a series of reports from Gilead Science, Inc describing symptomatic bradycardia events in nine patients treated with sofosbuvir with another DAA and amiodarone. ${ }^{2}$ In this update, bradycardia events were said to occur generally within hours to days, and a safety recommendation was made for patients who receive amiodarone to undergo cardiac monitoring for 48 hours after first administration. ${ }^{2}$

These warnings were based on anecdotal case reports or small case series ${ }^{3,4}$. However, uncertainty exists regarding the pathophysiological mechanisms underlying this putative association between sofosbuvir and cardiac/bradycardia events.

Therefore, we aimed to better estimate the risk of cardiac harms, with a special focus on arrhythmias, associated with sofosbuvir treatment by performing a systematic review of all randomized controlled trials (RCTs) comparing sofosbuvir with a control arm, independently of baseline conditions. 


\section{Methods}

This systematic review with meta-analysis was performed using Preferred Reporting Items for Systematic Reviews and Meta-analyses (PRISMA) framework guidelines for reporting guidance, ${ }^{5}$ as well as its extension for improving harms reporting in systematic reviews (PRISMA harms). ${ }^{6}$.

This systematic review was registered on PROSPERO (PROSPERO 2016:CRD42016033109) and the protocol can be accessed at www.crd.york.ac.uk/PROSPERO/display_record.asp?ID=CRD42016033109.

\section{$\underline{\text { Studies' eligibility criteria }}$}

We considered for inclusion all parallel design RCTs comparing any sofosbuvircontaining regimen (including sofosbuvir alone or with other active drugs, irrespective of the dose, treatment duration or route of administration) with non-sofosbuvir control arm (either placebo or no treatment). Studies were excluded if both arms have been exposed to sofosbuvir, or if none of the cardiac safety outcomes of interest was reported.

Cardiac safety was assessed by quantifying the risk of overall cardiac events (as defined by the System of Organ Classification - SOC - according to the MedDRA dictionary) reported in the RCTs, as well as the risk for arrhythmic events ${ }^{3,7}$, bradycardia ${ }^{3,7}$, tachycardia and extrasystoles (ventricular or supraventricular). Symptoms such as syncope, presyncope and loss of consciousness were also evaluated as potential surrogates of arrhythmic events. 


\section{$\underline{\text { Search method }}$}

Potential eligible studies were searched through an electronic search in MEDLINE, EMBASE and Cochrane Library (CENTRAL), performed in January 2017. Search strategy (Supplementary Data 1) included free-text and MeSH (Medical Subjects Headings) terms without language restrictions. RCTs were identified through methods previously published ${ }^{8,9}$. The reference lists of included studies as well as of other literature reviews were also comprehensively checked for other potential studies. Furthermore, we contacted the Clinical Research Department of Gillead Sciences, Inc to obtain further unpublished data.

\section{Data extraction, evaluation and synthesis}

Titles and abstract were screened independently by two authors. RCTs who potentially fulfilled the inclusion criteria were further assessed in full-text. Study characteristics and outcomes were extracted independently by two authors. As anticipated, we found different reported terms for the same adverse event. Therefore, in addition to an individual appraisal of such data, we have aggregated the reported adverse events into clinically meaningful groups/outcomes/symptoms, such as arrhythmias, bradycardia, tachycardia or extrasystoles. For example, if palpitations were reported as an adverse event, and further information was provided for its cause, e.g. sinus tachycardia, we classified this adverse event into two different categories. 


\section{$\underline{\text { Risk of bias in individual studies }}$}

We used the Cochrane tool for assessing risk of bias of included studies ${ }^{10}$. The six predefined specific domains of analysis were: random sequence generation, allocation concealment, blinding of participants and personnel, blinding of outcome assessment, incomplete outcome data, and selective reporting. A domain to assess if the events were independently adjudicated was added. Critical appraisal was performed independently by two authors. Any disagreement was solved by discussion and, if necessary, reached consensus with the participation of a third reviewer. The risk of bias was qualitatively evaluated as high, unclear or low risk. Risk of bias graphs were derived from this tool.

\section{$\underline{\text { Statistical analysis }}$}

RevMan 5.3.3 software was used to calculate individual studies estimates and pooled analyses estimates. Results were reported using risk ratio (RR) and 95\% confidence interval $(95 \% \mathrm{CI})$. RR was chosen as effect measure for primary analysis due to greater similarity of relative estimates between studies with different designs, populations and lengths of follow-up. ${ }^{11}$ Raw data from studies was converted to RR, and random-effects pooled analysis was performed using the Mantel-Haenszel statistical methods, irrespectively of the statistical heterogeneity, as assessed with the $\mathrm{I}^{2}$ test. $^{12}$ When one of the therapeutic arms presented zero events, a fixed value of 0.5 was added to avoid computational problems in the RR estimation ${ }^{13,14}$. As the events of interest are deemed to be infrequent, and in order to indirectly assess the robustness of the results found in primary analysis with the above mentioned methods, we also derived pooled estimates using the following alternative methods: 1) Peto's Odds Ratio (OR ${ }^{13}$; 2) Poisson random effects models for meta-analysis using the software $\mathrm{R}$ version 3.1.3, assuming 
similarities in the RR and incident risk ratio in the case of rare events ${ }^{15}$; 3) MantelHaenszel random effecs meta-analysis using the Risk Difference (RD) measure, in order to overcome the problems of zero events in both arms ${ }^{16}$.

\section{Assessment of confidence in cumulative evidence}

As recommended by the Grading of Recommendations Assessment, Development and Evaluation (GRADE) Working Group methodology ${ }^{17,18}$, two reviewers independently assessed all of the critical outcomes in the following domains: risk of bias, inconsistency, indirectness, imprecision and publication bias. In case of disagreement the authors reached consensus, consulting an independent third review if necessary. For this purpose, we used the GRADEprofiler (GRADEpro) software tool, which was then extract into the form of a summary of findings table for inclusion into the review manuscript. We applied the standard definitions of the quality of evidence ${ }^{19}$ and explicit criteria to ensure the consistency and reproducibility of GRADE judgements for each domain and for all key comparisons of the critical outcomes (Supplementary Data 2). 


\section{Results}

\section{Included trials}

Overall, six trials with 2346 patients fulfilled the inclusion criteria (Figure 1) ${ }^{20-25}$. A total 1625 patients were treated with sofosbuvir, either alone or in combination with other agents, such as ribarivin \pm peginterferon $(57 \%)$, velpatasvir $(38 \%)$ or ledispavir (5\%). Among controls, 349 patients were treated with placebo (4 trials), 243 patients were treated with the combination of interferon and ribavirine ( 1 trial), and 129 patients received the combination of elbasvir and grazoprevir ( 1 trial).

The mean age of patients in the trials ranged from 48 to 64 years, and the proportion of cirrhotic patients ranged from 16 to $100 \%$ among the trials.

Table 1 overviews the characteristics of the included trials.

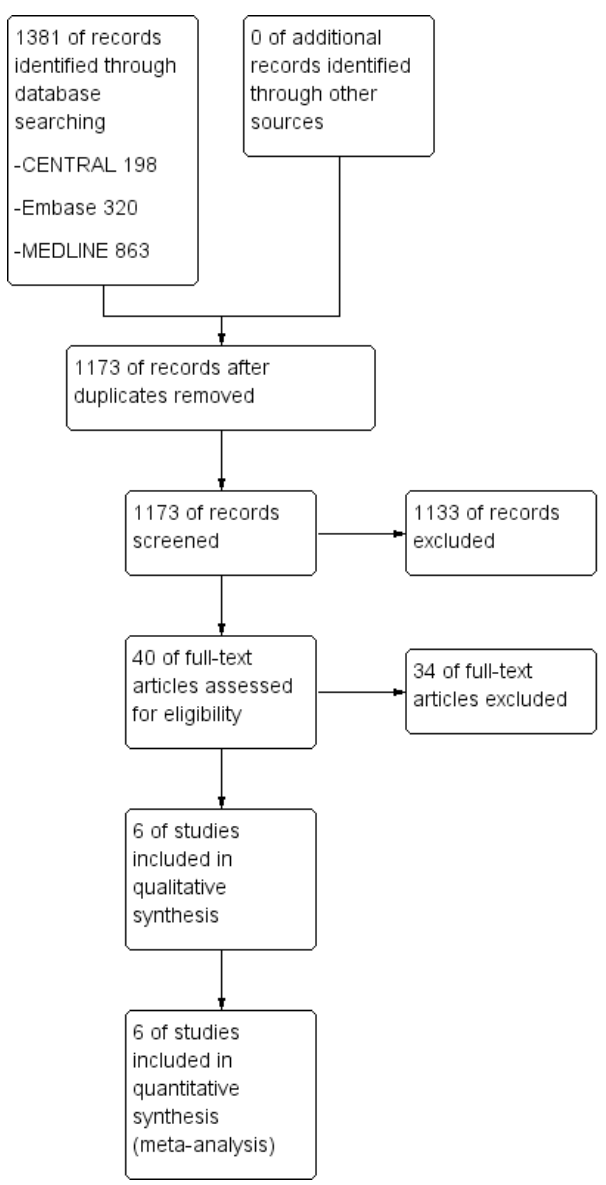


Figure 1: Flowchart of studies selection.

\section{$\underline{\text { Risk of bias }}$}

The overall risk of bias across studies was moderate. The included trials had different methodologic approaches which limits, at least partially, the robustness of data. All trials used adequate methods to randomize to therapeutic arms, but three trials were unblinded for the randomized arms: both FISSION and C-EDGE head-2-head trials had a priori an open-label design ${ }^{21,25}$, while in the VALENCE study ${ }^{22}$ randomization codes were revealed to terminate with the placebo arm due to the efficacy data reported in the FISSION trial ${ }^{21}$. In these trials the report of any adverse events could be done unblinded. Regarding the outcomes of interest of this systematic review, none was previously determined, and thus such events were not actively searched. None of adverse events reported was independently adjudicated. Figure 2 details the risk of bias assessment and Supplementary Figure 1 overviews the proportion of included trials that were at low or high risk of bias for each domain ascertained. 


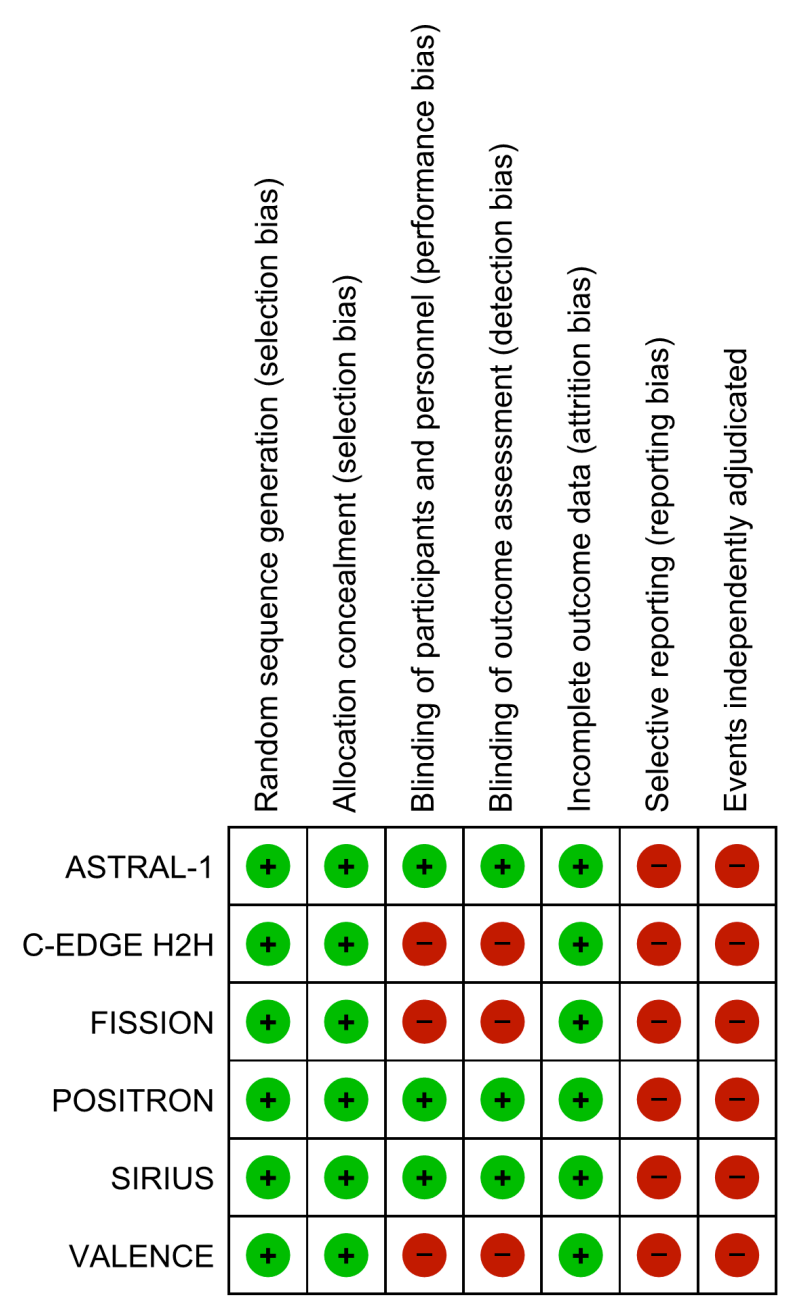

Figure 2: Risk of bias assessment results of each trial. Green symbols are associated to low risk of bias features, and red symbols mean high risk of bias. 
Table 1: Main characteristics of included trials.

\begin{tabular}{|c|c|c|c|c|c|c|c|c|}
\hline $\begin{array}{l}\text { Study } \\
\text { Year of } \\
\text { publication }\end{array}$ & Type of RCT & Patients & $\mathbf{N}$ & Intervention & Control & $\begin{array}{l}\text { Age } \\
\text { (years) / } \\
\text { Male (\%) }\end{array}$ & $\begin{array}{l}\text { Cirrhosis } \\
(\%)\end{array}$ & Follow-up \\
\hline $\begin{array}{l}\text { FISSION } \\
2013\end{array}$ & $\begin{array}{l}\text { Multicentric } \\
\text { Open-label }\end{array}$ & $\begin{array}{l}\text { Treatment-naïve patients with } \\
\text { HCV genotype } 2 \text { or } 3 \text { infection }\end{array}$ & 499 & $\begin{array}{l}\text { Sofosbuvir }+ \\
\text { Ribavirin } \\
(n=256)\end{array}$ & $\begin{array}{l}\text { Peginterferon }+ \\
\text { Ribavirin } \\
(n=243)\end{array}$ & $48 / 66 \%$ & $20 \%$ & $\begin{array}{l}12 \text { weeks after } \\
\text { the end of the } \\
\text { treatment }\end{array}$ \\
\hline $\begin{array}{l}\text { POSITRON } \\
2013\end{array}$ & $\begin{array}{l}\text { Multicentric } \\
\text { Blinded }\end{array}$ & $\begin{array}{l}\text { HCV genotype } 2 \text { or } 3 \text { infection } \\
\text { in whom treatment with } \\
\text { pegylated interferon and } \\
\text { ribavirin was not an option }\end{array}$ & 278 & $\begin{array}{l}\text { Sofosbuvir }+ \\
\text { Ribavirin } \\
(n=207)\end{array}$ & $\begin{array}{l}\text { Placebo } \\
(n=71)\end{array}$ & $52 / 54 \%$ & $16 \%$ & 12 weeks \\
\hline $\begin{array}{l}\text { VALENCE } \\
2014\end{array}$ & $\begin{array}{l}\text { Multicentric } \\
\text { Blinded } \\
\text { Unblinding due to } \\
\text { results of FISSION. } \\
\text { Placebo group was } \\
\text { terminated }\end{array}$ & HCV genotype 2 or 3 infection & 419 & $\begin{array}{l}\text { Sofosbuvir }+ \\
\text { Ribavirin } \\
(n=334)\end{array}$ & $\begin{array}{l}\text { Placebo } \\
(n=85) \\
\text { Early stop }\end{array}$ & $50 / 60 \%$ & $21 \%$ & $\begin{array}{l}24 \text { weeks } \\
7 \text { weeks for } \\
\text { placebo group }\end{array}$ \\
\hline $\begin{array}{l}\text { ASTRAL-1 } \\
2015\end{array}$ & $\begin{array}{l}\text { Multicentric } \\
\text { Blinded }\end{array}$ & $\begin{array}{l}\text { Previously treated patients } \\
\text { with chronic HCV genotype } 1 \text {, } \\
2,4,5 \text {, or } 6 \text { infection }\end{array}$ & 740 & $\begin{array}{l}\text { Sofosbuvir }+ \\
\text { velpatasvir } \\
(n=624)\end{array}$ & $\begin{array}{l}\text { Placebo } \\
(n=116)\end{array}$ & $64 / 60 \%$ & $19 \%$ & 12 weeks \\
\hline $\begin{array}{l}\text { SIRIUS } \\
2015\end{array}$ & $\begin{array}{l}\text { Multicentric French } \\
\text { trial } \\
\text { Blinded }\end{array}$ & $\begin{array}{l}\text { HCV genotype } 1 \text { and } \\
\text { compensated cirrhosis who } \\
\text { had not achieved SVR with } \\
\text { previous pegylated interferon } \\
\text { and protease inhibitor }\end{array}$ & 155 & $\begin{array}{l}\text { Sofosbuvir }+ \\
\text { Ledispavir } \\
(n=77)\end{array}$ & $\begin{array}{l}\text { Placebo in the } \\
\text { first } 12 \text { weeks } \\
(n=78)\end{array}$ & $57 / 74 \%$ & $100 \%$ & $\begin{array}{l}\text { First } 12 \text { weeks } \\
\text { of the trials }\end{array}$ \\
\hline $\begin{array}{l}\text { C-EDGE } \\
\text { Head-2- } \\
\text { Head } \\
2016\end{array}$ & $\begin{array}{l}\text { Multicentric } \\
\text { Open-label }\end{array}$ & $\begin{array}{l}\text { HCV genotype } 1 \text { or } 4 \text { infection } \\
\text { and baseline viral load }>10000 \\
\mathrm{IU} / \mathrm{ml}\end{array}$ & 255 & $\begin{array}{l}\text { Sofosbuvir }+ \\
\text { Peginterferon }+ \\
\text { Ribavirin } \\
(n=126)\end{array}$ & $\begin{array}{l}\text { Elbasvir }+ \\
\text { Grazoprevir }\end{array}$ & $50 / 46 \%$ & $17 \%$ & 12 weeks \\
\hline
\end{tabular}




\section{$\underline{\text { Primary analysis }}$}

The pooled analysis included both published and unpublished data (provided by Gilead Sciences, Inc.) from the 6 RCTs and showed that sofosbuvir was not associated with an increased risk of reported cardiac events (SOC cardiac), with a RR 0.87 (95\% 0.41 to $1.84, \mathrm{I}^{2}=7 \%, \mathrm{n}=2346$ ) (Figure 3 ). The risk of overall arrhythmic events was also not different between sofosbuvir regimens and non-sofosbuvir treatments (RR 0.93, 95\% CI 0.34 to $2.51, \mathrm{I}^{2}=0 \%, \mathrm{n}=2091$ ). As for bradycardia, only the FISSION trial reported such events: one sinus bradycardia in each arm, and one complete atrioventricular block in the interferon and ribavirine arm (non-sofosbuvir arm $)^{21}$. The RR for bradycardia was $0.47(95 \%$ CI 0.04 to $5.20, \mathrm{n}=499)$.

The pooled relative risk of tachycardia ( $\mathrm{RR} 1.13,95 \% \mathrm{CI} 0.28$ to $4.51, \mathrm{I}^{2}=0 \%, \mathrm{n}=1351$ ) and extrasystoles (RR 1.22, 95\%CI 0.25 to $5.89, \mathrm{I}^{2}=0 \%, \mathrm{n}=2091$ ) were not significantly different among sofosbuvir and non-sofosbuvir regimens.

Symptoms reported as adverse events potentially related to arrhythmias such as syncope, presyncope or loss of consciousness were reported in 3 trials (Figure 4). The pooled analyses of both individual outcomes (Supplementary Figure 2) and the composite of such reported adverse events (RR $0.70,95 \%$ CI 0.26 to $1.88, \mathrm{I}^{2}=0 \%$, $\mathrm{n}=1517$ ) did not show an increased risk with sofosbuvir treatment. Similarly, the relative frequency of palpitations as a reported adverse event was not increased with sofosbuvir (RR $0.62,95 \%$ CI 0.24 to $1.60, I^{2}=0 \%, n=1936$ ). 


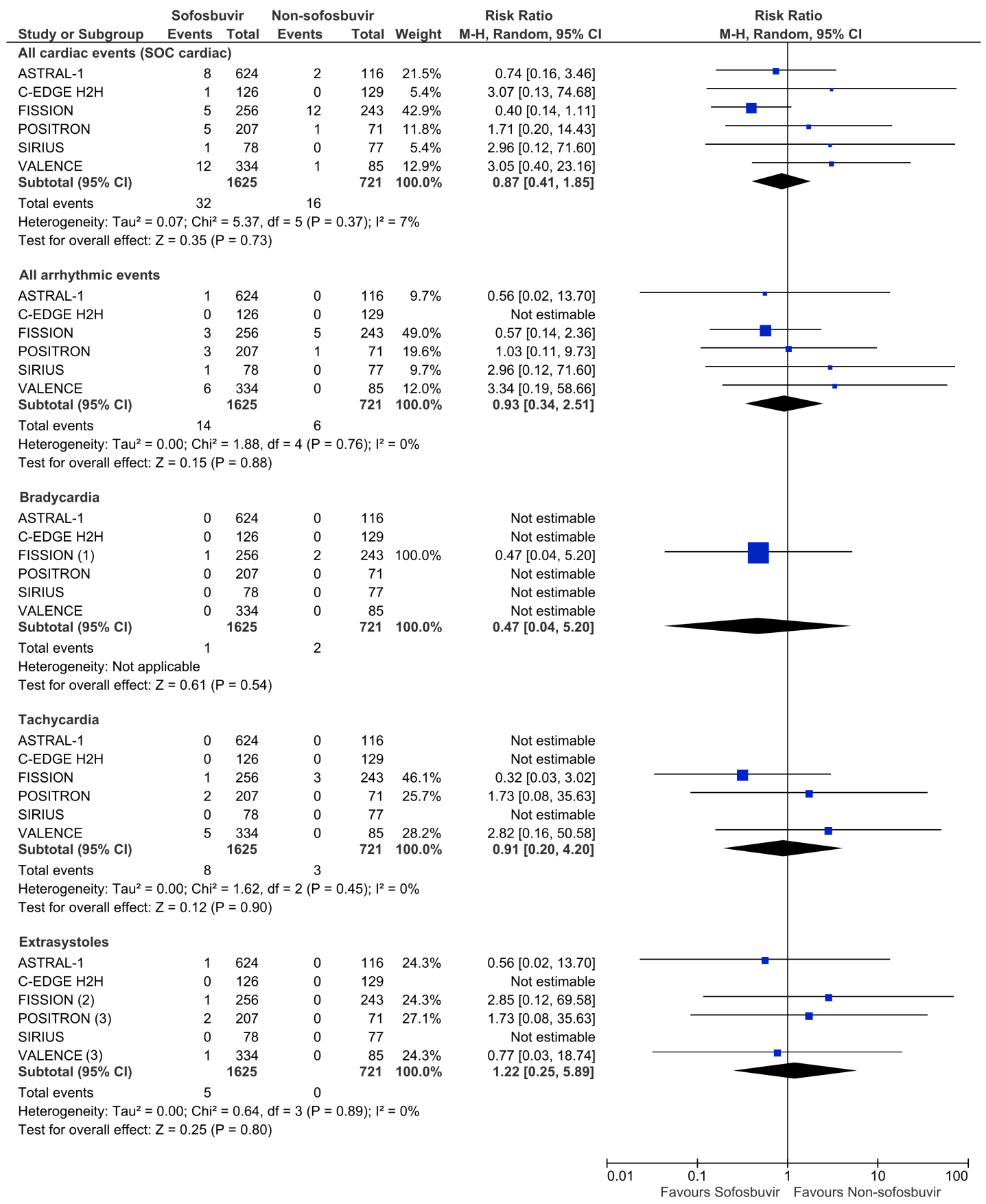

Footnotes

(1) One event of sinus bradycardia in each arm. One AV block in non-sofosbuvir arm.

(2) Extra-systoles with non-specified origin

(3) Ventricular extra-systoles

Figure 3: Forest plot evaluating the relative risk of reported cardiac events, arrhythmias, bradycardia, tachycardia, and extrasystoles. 


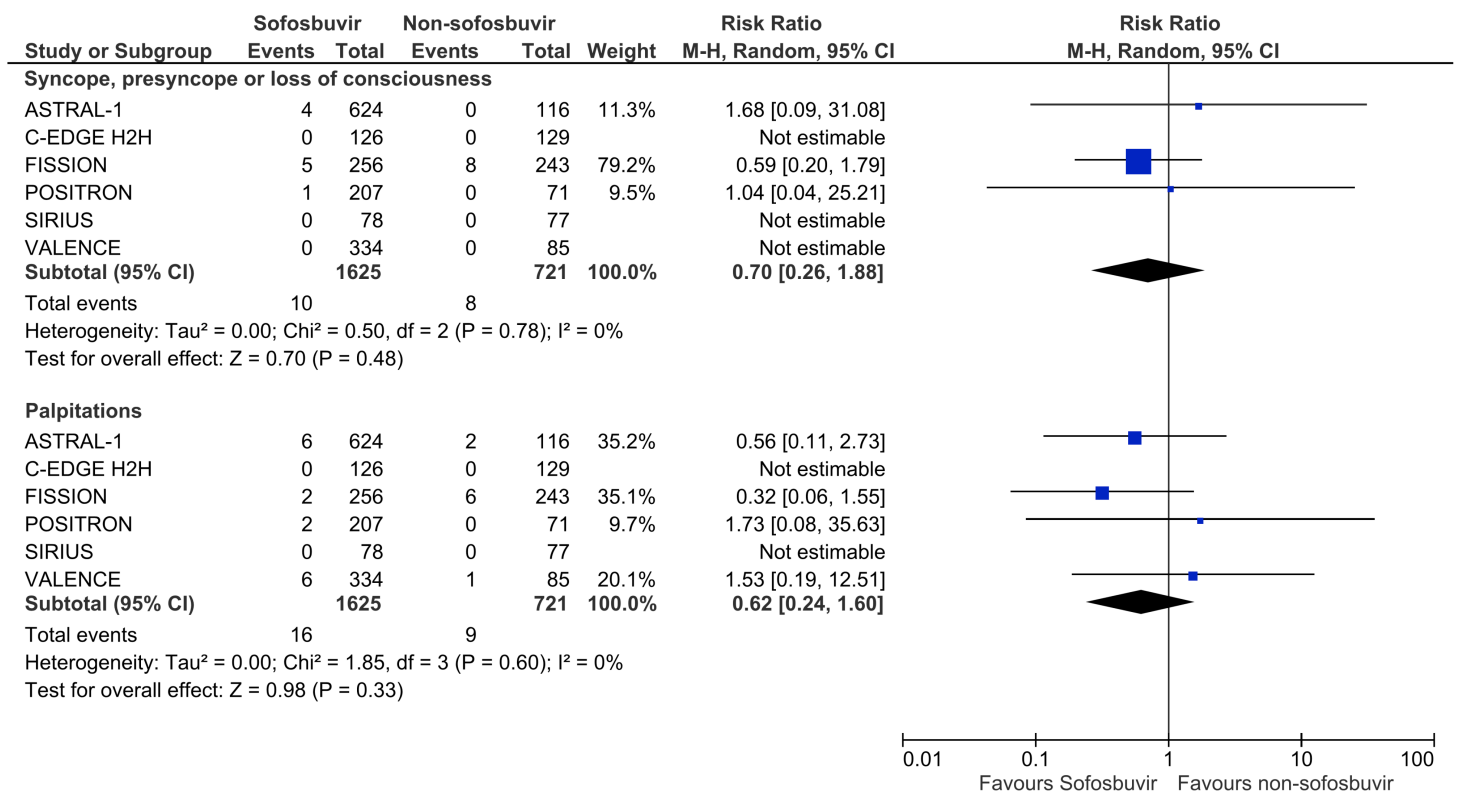

Figure 4: Forest plot evaluating the relative risk of the reported palpitations and cumulative outcome of syncope, presyncope or loss of consciousness.

\section{Additional analyses}

The results from pooled analyses using alternative methods and/or estimate measures were similar to the findings of primary analysis, without significant differences between groups for all outcomes (Table 2). 
Table 2: Risk of cardiac harms with sofosbuvir using alternative methods and/or estimate measures.

\begin{tabular}{|c|c|c|c|}
\hline & Peto's OR [95\% Cl] & $\begin{array}{l}\text { Poisson model - RR } \\
{[95 \% \mathrm{Cl}]}\end{array}$ & $\begin{array}{l}\text { Risk difference (\%) } \\
{[95 \% \mathrm{Cl}]}\end{array}$ \\
\hline $\begin{array}{l}\text { All cardiac events (SOC } \\
\text { cardiac) }\end{array}$ & $0.90[0.47,1.72]$ & $0.91[0.38,2.18]$ & $0.3 \%[-1.1,1.8]$ \\
\hline All arrhythmic events & $1.21[0.46,3.21]$ & $1.11[0.41,3.00]$ & $0.3 \%[-0.6,1.2]$ \\
\hline Bradycardia & $0.49[0.05,4.69]$ & $\mathrm{N} / \mathrm{A}$ & $-0.1 \%[-0.8,0.6]$ \\
\hline Tachycardia & $1.24[0.33,4.70]$ & $1.38[0.32,6.07]$ & $0.2 \%[-0.9,1.4]$ \\
\hline Extrasystoles & $4.35[0.57,33.50]$ & $\mathrm{N} / \mathrm{A}$ & $0.3 \%[-0.4,1.0]$ \\
\hline $\begin{array}{l}\text { Syncope, presyncope or } \\
\text { loss of consciousness }\end{array}$ & $0.82[0.30,2.21]$ & $0.73[0.27,1.97]$ & $0.2 \%[-0.7,1.0]$ \\
\hline Palpitations & $0.65[0.26,1.64]$ & $0.64[0.28,1.46]$ & $-0.2 \%[-1.4,0.8]$ \\
\hline
\end{tabular}

\section{$\underline{\text { Assessment of confidence in cumulative evidence }}$}

Supplementary Table 1 details the GRADE approach for the quality of the available evidence which was considered to be very low. 


\section{Discussion}

This systematic review overviewed cardiac events, which are of concerning in patients treated with sofosbuvir according to the last reports ${ }^{3,7}$.

Among the cardiac adverse events, arrhythmias, predominantly severe bradydysrhythmia, were deemed to be associated with sofosbuvir in particular circumstances.

Our systematic review and meta-analysis of RCTs evaluating sofosbuvir and nonsofosbuvir regimens (including placebo), did not raise any safety concerns regarding cardiac, arrhythmic or bradycardia risk. Complementarily, the analysis of reported adverse events related to symptoms linked to (but not pathognomonic of) dysrhythmias, such as syncope, presyncope, loss of consciousness, and palpitations was unremarkable for any safety warning issue, despite the acknowledged limitations (see Limitations section ahead).

Even though, the risk of arrhythmic events in patients with chronic liver disease and the potential causality with sofosbuvir (with or without amiodarone) should be addressed recognizing that some bias and drawbacks may exist. First, arrhythmias are not unusual in patients with chronic liver disease including cirrhosis ${ }^{26-29}$, and it is also known that the use of non-selective beta-blockers to decrease the portal pressure, further impairs the cardiac chronotropism and dromotropism ${ }^{30}$. Second, there are events occurring in patients without amiodarone ${ }^{7}$. Third, the causality relationship between sofosbuvir (and amiodarone) and the onset of bradycardia in the case reports and case-series is methodologically doubtful ${ }^{3,7}$. Thus, a reasonable uncertainty exists regarding sofosbuvir and the risk of cardiac/arrhythmic/bradycardic events.

Still, in 2015, the FDA issued a label update for both sofosbuvir and the combination of sofosbuvir and ledipasvir ${ }^{31}$. Gilead Sciences, Inc also issued a warning letter to 
physicians informing that both formulations of sofosbuvir may cause potentially fatal heart arrhythmias.

In our opinion, the present findings are of utmost clinical relevance: DAA are becoming the standard of care for hepatitis $\mathrm{C}$ treatment and the number of patients exposed to sofosbuvir is expected to be increasing in a proportion that exceeds the number of patients included the clinical trials. It is worth noting that the possibility of a small absolute risk increase is not excluded by our analysis and therefore larger observational studies or phase IV trials with longer follow-up will definitely contribute to the evaluation of cardiac risks associated with DAA, particularly sofosbuvir.

\section{$\underline{\text { Limitations }}$}

Results and conclusion here presented are weakened by limitations inherent to metaanalysis and individual studies. The higher risk of bias was found for potential selective reporting. A key limitation is that there is not a single RCT primarily designed to assess the cardiac/arrhythmic safety of sofosbuvir and these outcomes were not actively searched. Furthermore, reporting of cardiac events was at the discretion of the investigator. Another limitation of our findings is related to the low rates of cardiac events. In the sofosbuvir arms, the risk of overall cardiac events was about $2.0 \%$. Although the data from cardiac safety warnings points to potential short-term cardiac adverse events, it should be acknowledged that the follow-up period was considerably short and does not rule out the risk of long-term cardiac events. Even though, and considering these limitations, we claim that our results represent the best possible available evidence about this topic, which was raised by anecdotic case reports of potential idiosyncratic reactions that occurred in the first 48 hours in patients taking amiodarone and sofosbuvir. 


\section{Conclusions}

The best available evidence from RCTs does not confirm sofosbuvir as a harmful drug regarding short-term cardiac events, including (brady)arrhythmias.

Acknowledgements: We would like to thank to Gillead Sciences, Inc and Dr. Diana Brainard for providing unpublished safety data from sofosbuvir trials.

Funding: This was an academic project not funded by any government or nongovernment grant.

Competing interests: The authors have no competing interests to disclose.

Contributors: DC contributed to the concept and design and wrote the first draft of the manuscript; DC, FBR, MM, CS, MB contributed to data acquisition and data analysis. DC, FBR, MM, CS, MB, JJF and JC contributed to interpretation of data, critically revised the manuscript, and gave final approval of the submitted manuscript. DC is the guarantor. 


\section{References}

1. Yang HJ, Ryoo JY, Yoo BK. Meta-analysis of the efficacy and safety of sofosbuvir for the treatment of hepatitis C virus infection. International journal of clinical pharmacy 2015;37:698708.

2. FDA Drug Safety Communication: FDA warns of serious slowing of the heart rate when antiarrhythmic drug amiodarone is used with hepatitis $C$ treatments containing sofosbuvir (Harvoni) or Sovaldi in combination with another Direct Acting Antiviral drug. 2015. at http://www.fda.gov/Drugs/DrugSafety/ucm439484.htm.)

3. Renet S, Chaumais MC, Antonini T, et al. Extreme bradycardia after first doses of sofosbuvir and daclatasvir in patients receiving amiodarone: 2 cases including a rechallenge. Gastroenterology 2015;149:1378-80.e1.

4. Brainard DM, McHutchison JG. Bradyarrhythmias Associated with Sofosbuvir Treatment. The New England journal of medicine 2015;373:1888.

5. Liberati A, Altman DG, Tetzlaff J, et al. The PRISMA statement for reporting systematic reviews and meta-analyses of studies that evaluate healthcare interventions: explanation and elaboration2009.

6. Zorzela L, Loke YK, loannidis JP, et al. PRISMA harms checklist: improving harms reporting in systematic reviews. BMJ (Clinical research ed) 2016;352:i157.

7. Fontaine $\mathrm{H}$, Lazarus A, Pol S, et al. Bradyarrhythmias Associated with Sofosbuvir Treatment. The New England journal of medicine 2015;373:1886-8.

8. White VJ, Glanville JM, Lefebvre C, Sheldon TA. A statistical approach to designing search filters to find systematic reviews: objectivity enhances accuracy. Journal of Information Science 2001;27:357-70.

9. Glanville JM, Lefebvre C, Miles JN, Camosso-Stefinovic J. How to identify randomized controlled trials in MEDLINE: ten years on. Journal of the Medical Library Association : JMLA 2006;94:130-6.

10. Higgins JPT, Green S. Cochrane Handbook for Systematic Reviews of Interventions. 5.1.0 ed: John Wiley \&amp; Sons; 2011.

11. Deeks JJ. Issues in the selection of a summary statistic for meta-analysis of clinical trials with binary outcomes. Stat Med 2002;21:1575-600.

12. Higgins JP, Thompson SG. Quantifying heterogeneity in a meta-analysis. Stat Med 2002;21:1539-58.

13. Sweeting MJ, Sutton AJ, Lambert PC. What to add to nothing? Use and avoidance of continuity corrections in meta-analysis of sparse data. Statistics in medicine 2004;23:1351-75.

14. Bradburn MJ, Deeks JJ, Berlin JA, Russell Localio A. Much ado about nothing: a comparison of the performance of meta-analytical methods with rare events. Statistics in medicine 2007;26:53-77.

15. Cai T, Parast L, Ryan L. Meta-analysis for rare events. Statistics in medicine 2010;29:2078-89.

16. Friedrich JO, Adhikari NK, Beyene J. Inclusion of zero total event trials in meta-analyses maintains analytic consistency and incorporates all available data. BMC medical research methodology 2007;7:5.

17. Alonso-Coello P, Oxman AD, Moberg J, et al. GRADE Evidence to Decision (EtD) frameworks: a systematic and transparent approach to making well informed healthcare choices. 2: Clinical practice guidelines. Bmj 2016;353:i2089. 
18. Alonso-Coello P, Schunemann HJ, Moberg J, et al. GRADE Evidence to Decision (EtD) frameworks: a systematic and transparent approach to making well informed healthcare choices. 1: Introduction. Bmj 2016;353:i2016.

19. Balshem $\mathrm{H}$, Helfand $\mathrm{M}$, Schunemann $\mathrm{HJ}$, et al. GRADE guidelines: 3 . Rating the quality of evidence. Journal of clinical epidemiology 2011;64:401-6.

20. Jacobson IM, Gordon SC, Kowdley KV, et al. Sofosbuvir for hepatitis C genotype 2 or 3 in patients without treatment options. The New England journal of medicine 2013;368:186777.

21. Lawitz E, Mangia A, Wyles D, et al. Sofosbuvir for previously untreated chronic hepatitis C infection. The New England journal of medicine 2013;368:1878-87.

22. Zeuzem S, Dusheiko GM, Salupere R, et al. Sofosbuvir and ribavirin in HCV genotypes 2 and 3. The New England journal of medicine 2014;370:1993-2001.

23. Bourliere $M$, Bronowicki JP, de Ledinghen V, et al. Ledipasvir-sofosbuvir with or without ribavirin to treat patients with HCV genotype 1 infection and cirrhosis non-responsive to previous protease-inhibitor therapy: a randomised, double-blind, phase 2 trial (SIRIUS). The Lancet Infectious diseases 2015;15:397-404.

24. Feld JJ, Jacobson IM, Hezode C, et al. Sofosbuvir and Velpatasvir for HCV Genotype 1, 2, 4, 5, and 6 Infection. The New England journal of medicine 2015;373:2599-607.

25. Sperl J, Horvath G, Halota W, et al. Efficacy and safety of elbasvir/grazoprevir and sofosbuvir/pegylated interferon/ribavirin: A phase III randomized controlled trial. Journal of hepatology 2016;65:1112-9.

26. Josefsson A, Fu M, Bjornsson E, Kalaitzakis E. Prevalence of pre-transplant electrocardiographic abnormalities and post-transplant cardiac events in patients with liver cirrhosis. BMC gastroenterology 2014;14:65.

27. Mozos I. Arrhythmia risk in liver cirrhosis. World journal of hepatology 2015;7:662-72. 28. Karajamaki AJ, Patsi OP, Savolainen M, Kesaniemi YA, Huikuri H, Ukkola O. NonAlcoholic Fatty Liver Disease as a Predictor of Atrial Fibrillation in Middle-Aged Population (OPERA Study). PloS one 2015;10:e0142937.

29. Mantovani A, Ballestri S, Lonardo A, Targher G. Cardiovascular Disease and Myocardial Abnormalities in Nonalcoholic Fatty Liver Disease. Digestive diseases and sciences 2016;61:1246-67.

30. Ge PS, Runyon BA. The changing role of beta-blocker therapy in patients with cirrhosis. Journal of hepatology 2014;60:643-53.

31. FDA Hepatitis Update - Important safety information: Harvoni , and Sovaldi. 2015. at http://content.govdelivery.com/accounts/USFDA/bulletins/f97c71.) 


\section{Supplementary Data 1}

\section{Search strategy}

Database: MEDLINE and Cochrane Library (CENTRAL) via Ovid

1. Exp sofosbuvir/

2. Sofosbuvir.af

3. Sovaldi.af

4. Virunon.af

5. Harvoni.af

6. 1 or 2 or 3 or 4 or 5

7. randomized controlled trial.pt.

8. controlled clinical trial.pt.

9. randomized.ab.

10. drug therapy.fs.

11. randomly.ab.

12. trial.ab.

13. groups.ab.

14. 7 or 8 or 9 or 10 or 11 or 12 or 13

15. exp animals/ not humans.sh.

16. 14 not 15

17.6 and 16

Database: Embase Classic+Embase

1. exp sofosbuvir/

2. (sofosbuvir or sovaldi or virunon or harvoni).ti,ab.

3. 1 or 2

4. (random $\$$ or placebo $\$$ or single blind $\$$ or double blind $\$$ or triple blind $\$$ ).ti,ab.

5. RETRACTED ARTICLE/

6. 4 or 5

7. (animal\$ not human\$).sh,hw.

8. (book or conference paper or editorial or letter or review).pt. not exp randomized controlled trial/

9. (random sampl\$ or random digit\$ or random effect\$ or random survey or random regression).ti,ab. not exp randomized controlled trial/

10.7 or 8 or 9

11.6 not 10

12.3 and 11 


\section{Supplementary Data 2}

Definitions of the quality of evidence and criteria to each domain for all key comparisons of the critical outcomes.

Definitions of the quality of evidence:

- High quality: We are very confident that the true effect lies close to that of the estimate of the effect

- Moderate quality: We are moderately confident in the effect estimate; the true effect is likely to be close to the estimate of the effect, but there is a possibility that it is substantially different

- Low quality: Our confidence in the effect estimate is limited; the true effect may be substantially different from the estimate of the effect

- Very low quality: We have very little confidence in the effect estimate; the true effect is likely to be substantially different from the estimate of effect

\section{Criteria to each domain for all key comparisons of the critical outcomes:}

- Study limitations: downgraded once if more than 30\% of participants were from studies classified as being at a high risk of bias across any domain.

- Inconsistency: downgraded once if heterogeneity is statistically significant or if the $\mathrm{I}^{2}$ value is more than $40 \%$. When a meta-analysis was not performed we downgraded once if trials did not show effects in the same direction. 
- Indirectness: downgraded once if more than $50 \%$ of the participants were outside the target group.

- Imprecision: downgraded once if fewer than 300 events for dichotomous data.

- Publication bias: downgraded once where there is direct evidence of publication bias or if estimates of effect were based on small scale, industry-sponsored studies raising a considerable suspicion of publication bias. 
Random sequence generation (selection bias)

Allocation concealment (selection bias)

Blinding of participants and personnel (performance bias)

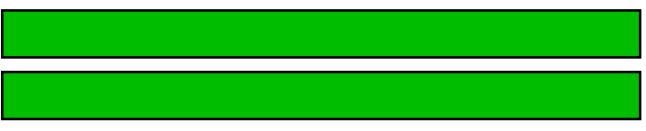

\section{Blinding of outcome assessment (detection bias) \\ Incomplete outcome data (attrition bias) \\ Selective reporting (reporting bias)
Events independently adjudicated
Events independently adjudicated
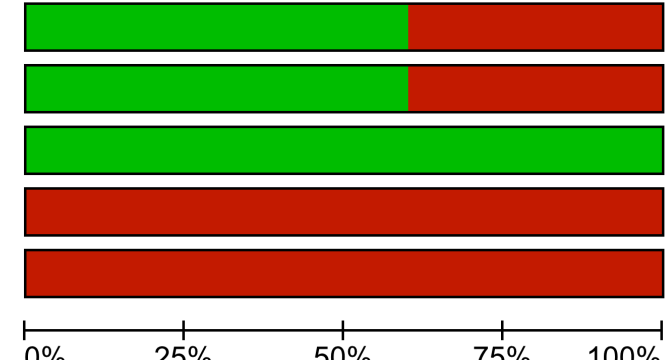

Low risk of bias

Unclear risk of bias

High risk of bias

Supplementary Figure 1: Risk of bias graph: review authors' judgements about each risk of bias item presented as percentages across all included studies.

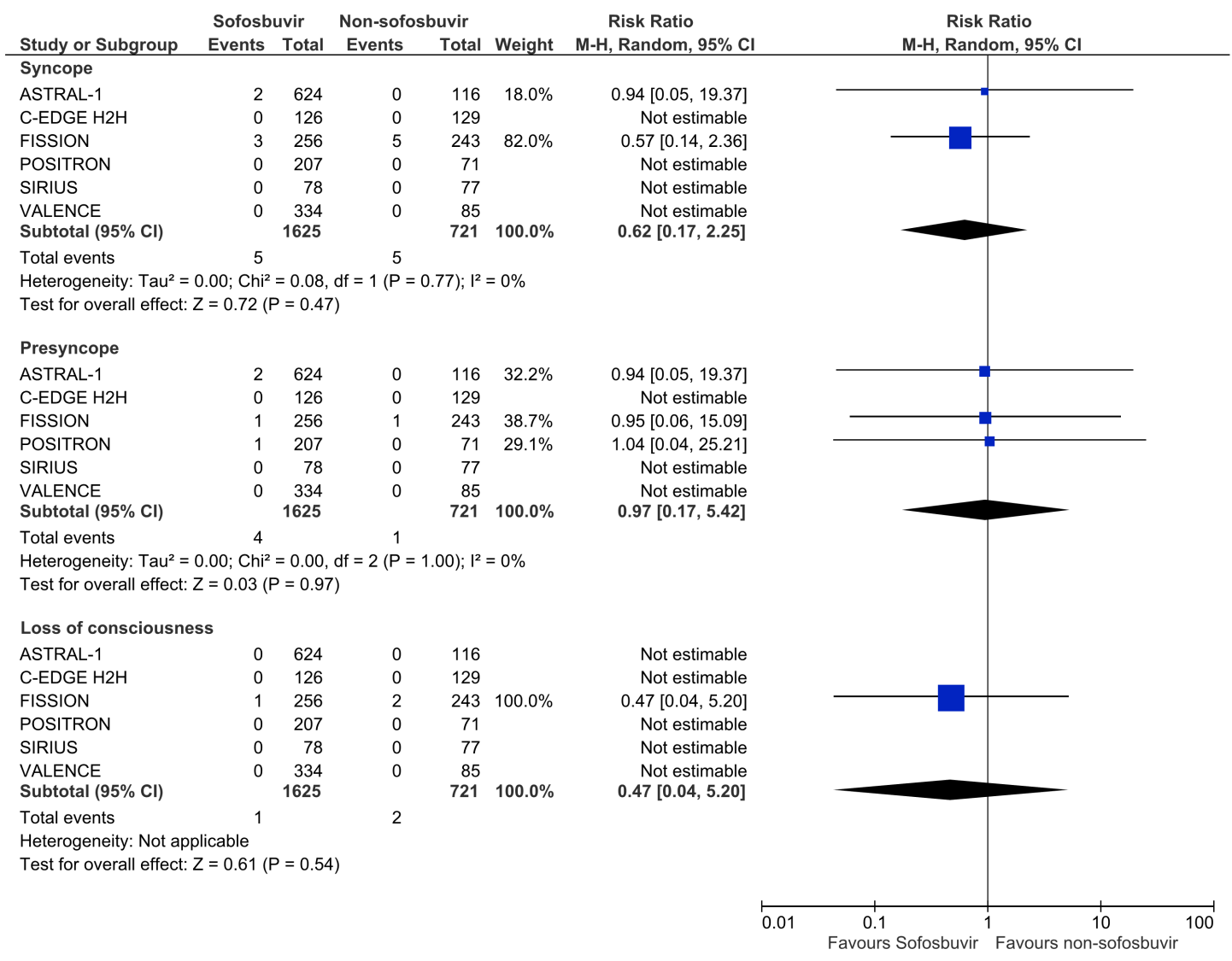

Supplementary Figure 2: Forest plot evaluating the relative risk of the reported syncope, presyncope or loss of consciousness associated to sofosbuvir regimens. 
Supplementary Table 1 - Summary of findings table according to the GRADE

approach.

\begin{tabular}{|c|c|c|c|c|c|}
\hline \multirow{2}{*}{$\begin{array}{l}\text { Outcome } \\
\text { № of participants } \\
\text { (studies) }\end{array}$} & \multirow{2}{*}{$\begin{array}{l}\text { Relative effect } \\
(95 \% \mathrm{Cl})\end{array}$} & \multicolumn{3}{|c|}{ Anticipated absolute effects $(95 \% \mathrm{Cl})$} & \multirow[t]{2}{*}{ Quality } \\
\hline & & Without Sofosbuvir & With Sofosbuvir & Difference & \\
\hline $\begin{array}{l}\text { All cardiac events (SOC cardiac) } \\
\text { № of participants: } 2346 \\
\text { (6 RCTs) }\end{array}$ & $\begin{array}{l}\text { RR } 0.87 \\
\text { (0.41 to } 1.82)\end{array}$ & $2.2 \%$ & $\begin{array}{l}1.9 \% \\
(0.9 \text { to } 4.0)\end{array}$ & $\begin{array}{l}0.3 \% \text { fewer } \\
(1.3 \text { fewer to } \\
1.8 \text { more })\end{array}$ & \\
\hline $\begin{array}{l}\text { All arrhythmic events } \\
\text { № of participants: } 2091 \\
\text { (5 RCTs) }\end{array}$ & $\begin{array}{l}\text { RR } 0.93 \\
\text { (0.34 to } 2.51)\end{array}$ & $1.0 \%$ & $\begin{array}{l}0.9 \% \\
(0.3 \text { to } 2.5)\end{array}$ & $\begin{array}{l}0.1 \% \text { fewer } \\
(0.7 \text { fewer to } \\
1.5 \text { more })\end{array}$ & $\begin{array}{l}\text { VER } \\
a, b\end{array}$ \\
\hline $\begin{array}{l}\text { Bradycardia } \\
\text { № of participants: } 499 \\
\text { (1 RCT) }\end{array}$ & $\begin{array}{l}\text { RR } 0.47 \\
\text { (0.04 to } 5.20)\end{array}$ & $0.8 \%$ & $\begin{array}{l}0.4 \% \\
(0.0 \text { to } 4.3)\end{array}$ & $\begin{array}{l}\mathbf{0 . 4 \%} \text { fewer } \\
(0.8 \text { fewer to } \\
3.5 \text { more })\end{array}$ & $\begin{array}{l}\text { VERY LOW } \\
a, b\end{array}$ \\
\hline $\begin{array}{l}\text { Tachycardia } \\
\text { № of participants: } 1351 \\
\text { (4 RCTs) }\end{array}$ & $\begin{array}{l}\text { RR } 1.13 \\
(0.28 \text { to } 4.51)\end{array}$ & $0.6 \%$ & $\begin{array}{l}0.7 \% \\
(0.2 \text { to } 2.8)\end{array}$ & $\begin{array}{l}0.1 \% \text { more } \\
(0.5 \text { fewer to } \\
2.2 \text { more })\end{array}$ & $\underset{a, b}{\text { VERY LOW }}$ \\
\hline $\begin{array}{l}\text { Extrasystoles } \\
\text { № of participants: } 1936 \\
\text { (4 RCTs) }\end{array}$ & $\begin{array}{l}\text { RR } 1.22 \\
(0.25 \text { to } 5.89)\end{array}$ & $0.0 \%$ & $\begin{array}{l}0.0 \% \\
(0.0 \text { to } 0.0)\end{array}$ & $\begin{array}{l}\mathbf{0 . 0 \%} \text { fewer } \\
(0 \text { fewer to } 0 \\
\text { fewer) }\end{array}$ & $\begin{array}{l}\text { VER } \\
a, b\end{array}$ \\
\hline $\begin{array}{l}\text { Syncope, presyncope or loss of consciousness } \\
\text { № of participants: } 1517 \\
\text { (3 RCTs) }\end{array}$ & $\begin{array}{l}\text { RR } 0.70 \\
(0.26 \text { to } 1.88)\end{array}$ & $1.9 \%$ & $\begin{array}{l}1.3 \% \\
(0.5 \text { to } 3.5)\end{array}$ & $\begin{array}{l}0.6 \% \text { fewer } \\
(1.4 \text { fewer to } \\
1.6 \text { more })\end{array}$ & $\begin{array}{l}\text { VERY LOW } \\
a, b\end{array}$ \\
\hline $\begin{array}{l}\text { Palpitations } \\
\text { № of participants: } 1936 \\
\text { (4 RCTs) }\end{array}$ & $\begin{array}{l}\text { RR } 0.62 \\
\text { (0.24 to } 1.60)\end{array}$ & $1.7 \%$ & $\begin{array}{l}1.1 \% \\
(0.4 \text { to } 2.8)\end{array}$ & $\begin{array}{l}\mathbf{0 . 7 \%} \text { fewer } \\
(1.3 \text { fewer to } \\
1 \text { more })\end{array}$ & $\begin{array}{l}\text { VERY LOW } \\
a, b\end{array}$ \\
\hline
\end{tabular}

*The risk in the intervention group (and its $95 \%$ confidence interval) is based on the assumed risk in the comparison group and the relative effect of the intervention (and its $95 \% \mathrm{Cl}$ ). Cl: Confidence interval; RR: Risk ratio

\section{GRADE Working Group grades of evidence}

High quality: We are very confident that the true effect lies close to that of the estimate of the effect; Moderate quality: We are moderately confident in the effect estimate: The true effect is likely to be close to the estimate of the effect, but there is a possibility that it is substantially different; Low quality: Our confidence in the effect estimate is limited: The true effect may be substantially different from the estimate of the effect; Very low quality: We have very little confidence in the effect estimate: The true effect is likely to be substantially different from the estimate of effect

a. Serious study limitations: the limitations in the studies assessing this outcome are serious and affect our confidence in the accuracy of the effect estimate

b. Very serious imprecision: the total number of participants included was less than $10 \%$ of the number generated by a conventional sample size calculation single adequately powered superiority trial (alpha $=0.05$, beta $=0.20$ ) 